\title{
QUANTUM CHEMICAL COMPUTATIONAL STUDIES ON A VIC-DIOXIME LIGAND AND ITS NICKEL COMPLEX
}

\author{
Ayşin ZÜLFİKAROĞLU * \\ Department of Chemistry, Faculty of Arts and Sciences, Amasya University, Amasya, Turkey,
}

\begin{abstract}
In this study, the structural and bonding characteristic of 1-(2,6-Dimethylphenylamino)propane-1,2-dione dioxime ligand and its nickel (II) complex were examined by means of quantum chemical computations. Primarily, comprehensive calculations were performed on these compounds with semi-empirical, Density-functional theory and Hartree-Fock methods by using different basis sets. The structural accuracy of ligand and complex were investigated by comparing the calculated values to the bond lengths and angles measured in X-ray structures. Then, comparison of the methods was made by considering quality factors calculated for different basis sets of each method. The theoretical structural studies on ligand and complex were carried out by Ultraviolet-Visible, Fourier Transform Infrared and Nuclear Magnetic Resonance spectral analysis. The calculated vibrational bands, electronic absorption spectrum and NMR chemical shifts were determined to be consistent with the experimental results. In addition, the characteristic of the metal-ligand interactions were demonstrated by natural bond orbital analysis.
\end{abstract}

Keywords: vic-Dioxime, Nickel(II) complex, DFT, HF, Semi-emprical method

\section{INTRODUCTION}

vic-Dioximes and their metal complexes have attracted considerable attention for their electrochemical and analytical properties and their widespread uses in many important chemical operations in the fields of catalysis, medicine and metallurgy. vic-Dioximes ligands capable of coordinating through $\mathrm{N}, \mathrm{N}$ or $\mathrm{N}, \mathrm{O}$ donor atoms form the coordination compounds having extraordinary stability and excellent electronic properties with transition metal ions. The nickel(II) vic-dioxime complexes which were first discovered by Tschugaev are used in many analytical methods such as voltammetry, thermal decomposition and spectrophotometry [1,2].

With the vast development of computational chemistry in the past decade, it is possible to describe correctly the chemical and physical properties of organic molecules and metal complexes from first principles using various computational techniques [3-9]. The theoretical studies on oximes and their coordination compounds have attracted a great deal of attention in recent years. Experimental studies on oximes and their metal complexes were crosschecked by theoretical calculations. The computational methods provide geometry optimization in order to determine the most stable structures of these compounds and allow to study spectroscopic properties with reproduce the experimental values in terms of electronic transitions, chemical shifts and vibrational frequency [9]. However, there are not enough studies on the vic-dioximes and their metal complexes in terms of the quantum chemical and spectroscopic properties in the literature. In previous works, 1-(2,6-Dimethylphenylamino)propone-1,2dione dioxime ligand containing vic-dioxime group (Figure 1) and its nickel (II) complex (Figure 2) was synthesized and characterized by Fouier Transform Infrared (FT-IR), Nuclear Magnetic Resonance (NMR), Ultraviolet-Visible (UV-Vis.) spectral data and X-ray diffraction [10-12]. In this study, comprehensive quantum chemical calculations were performed on these compounds. Molecular parameters of the compounds were optimized by using Density-functional theory (DFT), Hartree-Fock (HF) and semi-emprical methods with different basis sets. The ground state bond lengths and angles for 
the optimized structures were compared with X-ray diffraction results. The comparison of theory and basis sets used for the calculation were carried out with the quality factor Q [13] calculated for each method. The vibrational spectra and assignments, ${ }^{1} \mathrm{H}$ NMR spectra and electronic absorption spectra were investigated on ligand and its complex. The results indicate that these calculations are helpful for understanding the molecular properties of vic-dioxime ligand and its nickel (II) complex. The atomic charges of the ligand were calculated to investigate its possible coordination modes by natural bond orbital (NBO) [14] analysis. The metal-ligand interactions were also explored on the basis of natural charges and the computed second-order perturbation energies [14]. These calculations are valuable for providing insight into molecular properties of similar vic-dioxime compounds and vic-dioxime metal complexes.

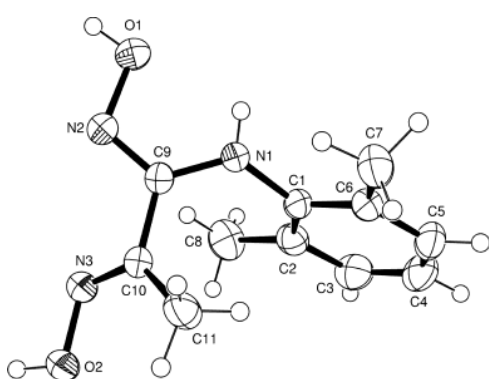

(a)

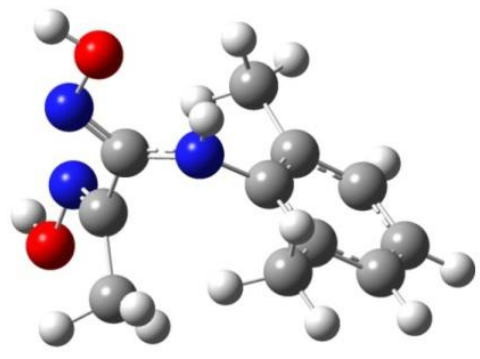

(b)

Figure 1. (a) X-ray [10] and (b) optimized structures of vic-dioxime ligand (red= oxygen; blue = nitrogen; gray = carbon; white $=$ hydrogen)

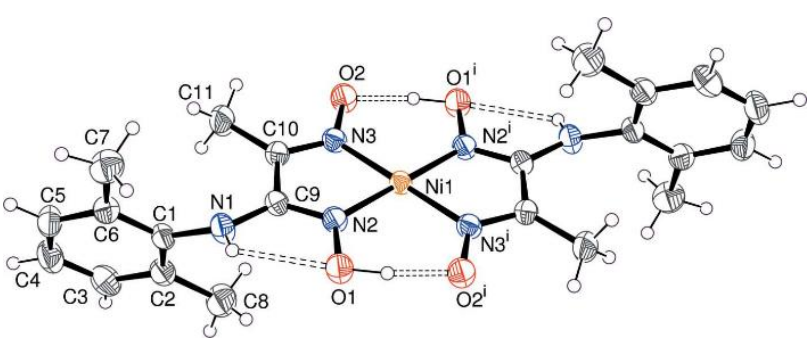

(a)

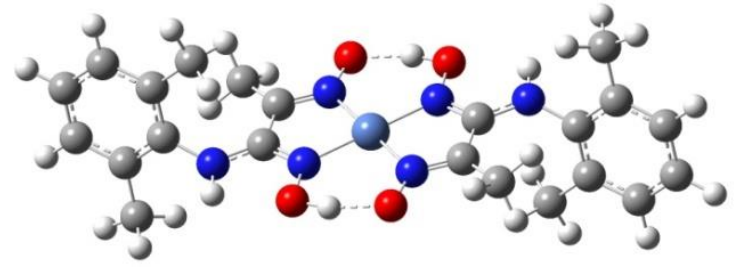

(b)

Figure 2. (a) X-ray [12] and (b) optimized structures of vic-dioxime Ni(II) complex (red= oxygen; blue = nitrogen; gray $=$ carbon; white $=$ hydrogen)

\section{COMPUTATIONAL DETAILS}

All of the computations were carried out with the Gaussian 09 program package and the GaussView 5 molecular visualization program $[15,16]$. The molecular geometry of the vic-dioxime ligand and its nickel (II) complex were taken directly from the X-ray diffraction experimental results without any restriction. The molecular structures of the ligand and complex in the ground state (in vacuo) were optimized by density functional theory / The Becke's three parameter hybrid functional and Lee-YangParr correlation functionals (DFT/B3LYP) [17-19] and Hartree Fock (HF) [20] methods with nine different basis sets [3-21G, 6-31G, 6-31G(d), 6-31+G(d), 6-311+G(d), 6-311+G(2d), 6-311++G(d), 6$311++\mathrm{G}(2 \mathrm{~d})$, LANL2DZ]. The basis sets were enlarged starting from the smallest basis set $3-21 \mathrm{G}$. Besides, semi-empirical computational optimizations were made on the basis of the AM1 [21], PM3 [22] and PM6 [23] methods.

The vibrational harmonic frequencies of the title complex were calculated using the DFT/B3LYP hybrid functional with 6-31G(d) and 6-311++G(2d) basis sets and HF method with 6-31G(d) basis set. Vibrational band assignments were made using the Gauss-View molecular visualization program [16]. 
The obtained frequencies were commented without scaling. The geometry of these compounds was fully optimized together with that of tetramethylsilane (TMS). The theoretical ${ }^{1} \mathrm{H}$ NMR chemical shift values were calculated within GIAO (the Gauge-Independent Atomic Orbital) approach [24] applying DFT method with B3LYP/6-31G(d), B3LYP/6-311++G(2d) basis sets and HF method with 6-31G(d) basis set in dimethyl sulfoxide (DMSO) solvent. The ${ }^{1} \mathrm{H}$ NMR chemical shifts are converted into the TMS scale by subtracting the calculated absolute chemical shielding of TMS whose value as $32.16 \mathrm{ppm}$ for B3LYP/631G(d) level, $32.34 \mathrm{ppm}$ for B3LYP/6- 311++G(2d) level and $32.89 \mathrm{ppm}$ for HF/6- 31G(d) level. The electronic absorption maximum wavelengths $(\lambda \max )$ in DMSO solvent were calculated using the timedependent DFT (TD-DFT) method at B3LYP/6-31G(d) level $[25,26]$. Natural bond orbital (NBO) analyses [27] were performed to investigate the metal-ligand interactions using the NBO 3.1 program.

\section{RESULTS AND DISCUSSION}

\subsection{Geometry Optimization Calculations and Comparison of Different Methods}

The crystal structures of the vic-dioxime ligand and its nickel (II) complex were formerly determined using the single crystal X-ray method [11, 12]. In the complex, nickel atom was found to be coordinated by four oxime $\mathrm{N}$ atoms resulting from two bidentate ligand molecules.

The computed structures for the ligand and its complex were achieved using the semi-empirical, HF and DFT methods. These structures were compared with crystallographically obtained structures. The accuracy was calculated as percentage error as shown in equation 1 to determine whether there was good agreement between the calculated bond parameters and those detected from X-ray analysis. The calculated bond length and angle errors are shown in Table 1 . The molecular structures of the ligand and its complex are shown in Figure 1 and 2, respectively.

$$
\text { Error }(\%)=\frac{\mid \text { Calculate value }-\mathrm{X} \text { ray value } \mid}{\mathrm{X} \text { ray value }} \times 100 \%
$$

Semi-empirical computational optimization for the ligand and its complex were performed on the basis of the PM3, PM6 and AM1 methods. While all semi-empirical methods gave a suitable structure for the ligand, only the PM6 method gave successful results for the complex. Among the methods used for optimization, DFT method generally gives better results for bond parameters with less errors than other two methods.

The quality of the reproducibility was surveyed by the quality factor $Q$ defined equation 2 [13].

$$
\mathrm{Q}=1-\sum_{0}^{\mathrm{n}}\left(\frac{\mathrm{a}_{\text {calc }}}{\mathrm{a}_{\mathrm{obs}}}-1\right)^{2} / \mathrm{n}
$$

The quality factor $(\mathrm{Q})$ values are very useful in comparing the computational methods used in the quantum chemical calculations of a molecule. The fact that the $\mathrm{Q}$ value calculated for a computational method is close to 1 indicates that the calculated bond parameters are in good agreement with those measured by X-ray diffraction and the calculation method could be successfully reproduced the crystal structure. It can be said that the bigger the $Q$ value, the better the quality [13]. In order to determine the computational method or methods which can produce the closest structures to the X-ray structures of the ligand and complex, the quality factor $(\mathrm{Q})$ values for different basis sets of DFT and HF methods used in optimization of the ligand and its complex were calculated by using the Formula 2. The acalc and $\mathrm{a}_{\mathrm{obs}}$ in the formula are correspond to the bond parameters (length and angle) that are calculated and detected from X-ray analysis, respectively. The obtained Q values are shown graphically in Figure 3 and 4. 
Table 1. Calculated bond length and angle errors for vic-dioxime ligand and its $\mathrm{Ni(II)} \mathrm{complex}$

\begin{tabular}{|c|c|c|c|c|c|c|c|}
\hline & \multirow[b]{3}{*}{ Method } & \multicolumn{3}{|c|}{ Deviations in bond length \% } & \multicolumn{3}{|c|}{ Deviations in bond angles \% } \\
\hline & & \multirow{2}{*}{\begin{tabular}{|l|}
\multicolumn{1}{|c}{ Ligand } \\
Non- \\
hydrogen \\
atoms
\end{tabular}} & \multicolumn{2}{|c|}{ Nickel Complex } & \multirow{2}{*}{\begin{tabular}{|l|}
\multicolumn{1}{|c|}{ Ligand } \\
Non- \\
hydrogen \\
atoms
\end{tabular}} & \multicolumn{2}{|c|}{ Nickel Complex } \\
\hline & & & $\begin{array}{l}\text { Around } \\
\text { nickel }\end{array}$ & $\begin{array}{l}\text { Non-hydrogen } \\
\text { atoms except } \\
\text { for nickel } \\
\end{array}$ & & $\begin{array}{l}\text { Around } \\
\text { nickel }\end{array}$ & $\begin{array}{l}\text { Non-hydrogen } \\
\text { atoms except } \\
\text { for nickel } \\
\end{array}$ \\
\hline \multirow{9}{*}{$\bar{\imath}$} & B3LYP/3-21G & $5.73-0,14$ & $2.39-2.18$ & $4.04-0.07$ & 5.09-0.10 & $11.42-0.21$ & $2.63-0.03$ \\
\hline & B3LYP/6-31G & $4.51-0.46$ & $0.72-0.62$ & $2.57-0.01$ & $1.74-0.01$ & $0.66-0.00$ & $2.76-0.01$ \\
\hline & B3LYP/6-31G(d) & $0.57-0.80$ & $0.89-0.71$ & $1.86-0.10$ & $2.16-0.01$ & $1.21-0.00$ & $2.02-0.09$ \\
\hline & B3LYP/6-31+G(d) & $1.69-0.16$ & $1.75-1.67$ & $1.67-0.09$ & $1.30-0.03$ & $0.55-0.00$ & $2.46-0.03$ \\
\hline & B3LYP/6-311+G(d) & $1.48-0.07$ & $1.98-1.95$ & $2.12-0.04$ & $1.31-0.02$ & $0.59-0.00$ & $2.51-0.01$ \\
\hline & B3LYP/6-311+G(2d) & $1.90-0.00$ & $1.81-1.80$ & $1.90-1.01$ & $1.26-0.05$ & $0.68-0.00$ & $2.43-0.01$ \\
\hline & B3LYP/6-311++G(d) & $1.48-0.07$ & $1.98-1.96$ & $2.11-0.06$ & $1.30-0.02$ & $0.60-0.01$ & $2.45-0.02$ \\
\hline & B3LYP/6-311++G(2d) & $1.28-0.00$ & $1.81-1.80$ & $1.90-0.01$ & $1.25-0.05$ & $0.67-0.00$ & $2.42-0.01$ \\
\hline & B3LYP/LANL2DZ & $4.23-0.14$ & $1.68-1.52$ & $2.40-0.16$ & $1.49-0.02$ & $0.75-0.00$ & $2.88-0.04$ \\
\hline \multirow{9}{*}{ 玍 } & 3-21G & $3.37-0.07$ & $1.28-1.24$ & $4.27-0.17$ & $6.58-0.03$ & $0.66-0.03$ & $3.53-0.24$ \\
\hline & 6-31G & $1.40-0.00$ & $3.79-3.75$ & $2.27-0.07$ & 2.82-0.06 & \begin{tabular}{|l|}
$1.91-0.00$ \\
\end{tabular} & \begin{tabular}{|l|}
$4.61-0.09$ \\
\end{tabular} \\
\hline & 6-31G(d) & $2.39-0.00$ & $3.89-3.74$ & $3.28-0.13$ & $1.01-0.35$ & $1.63-0.00$ & $4.91-0.12$ \\
\hline & 6-31+G(d) & $2.46-0.00$ & \begin{tabular}{|l|}
$4.60-3.87$ \\
\end{tabular} & $2.87-0.13$ & 0.91-0.42 & 1.69-0.00 & 3.33-0.08 \\
\hline & 6-311+G(d) & $2.81-0.00$ & $4.92-4.02$ & $3.34-0.20$ & $1.08-0.41$ & $1.85-0.00$ & $3.15-0.09$ \\
\hline & 6-311+G(2d) & $2.67-0.07$ & 4.81-3.95 & $3.14-0.15$ & $1.23-052$ & $4.17-0.00$ & $2.88-0.02$ \\
\hline & 6-311++G(d) & $2.81-0.00$ & $4.92-4.03$ & $3.34-0.20$ & $1.06-0.42$ & $1.85-0.00$ & $3.16-0.08$ \\
\hline & 6-311++G(2d) & $2.67-0.07$ & \begin{tabular}{|l|}
$4.82-3.95$ \\
\end{tabular} & $3.12-0.15$ & 1.21-0.52 & \begin{tabular}{|l|}
$1.71-0.00$ \\
\end{tabular} & \begin{tabular}{|l|}
$2.90-0.02$ \\
\end{tabular} \\
\hline & LANL2DZ & $1.69-0.00$ & $4.08-3.98$ & $2.46-0.01$ & $2.18-0.29$ & $2.24-0.00$ & $4.29-0.01$ \\
\hline \multirow{3}{*}{ 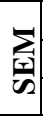 } & AM1 & $7.31-0.07$ & \multicolumn{2}{|c|}{ Failed } & $7.11-0.12$ & \multicolumn{2}{|c|}{ Failed } \\
\hline & PM3 & $5.52-0.00$ & \multicolumn{2}{|c|}{ Failed } & $8.38-0.06$ & \multicolumn{2}{|c|}{ Failed } \\
\hline & PM6 & $4.57-0.29$ & $2.93-0.23$ & $4.01-0.01$ & $6.67-0.12$ & $2.06-0.00$ & $3.62-0.01$ \\
\hline
\end{tabular}

As can be seen in the graph in the Figure $3 a$ where the results of the basis sets used with the DFT/B3LYP method in ligand optimization were compared, the $Q$ values of $6-31 \mathrm{G}(\mathrm{d}), 6-31+\mathrm{G}(\mathrm{d}), 6-311+\mathrm{G}(\mathrm{d}), 6-$ $311+\mathrm{G}(2 \mathrm{~d}), 6-311++\mathrm{G}(\mathrm{d}), 6-311++\mathrm{G}(2 \mathrm{~d})$ are very close to each other and higher than those of other basis sets, especially for bond lengths. It can be concluded that these basis sets reproduced better bond lengths of the ligand than other basis sets. Moreover, all basis sets except 3-21G gave similar and quite good results for bond angles of this compound.

When the same comparison is made for the HF method (Fig 3b), it can be said that the 6-31G and LANL2DZ basis sets with slightly higher $Q$ values than those of others are slightly more successful in producing bond lengths of the ligand. For bond angles, the other basis sets except 3-21G gave very similar results.

The Q values of the DFT and HF methods for same basis sets indicated that the DFT/B3LYP method with large basis sets reproduced bond parameters of the ligand better than HF. For DFT and HF methods, the calculated Q values generally do not change much with the enlargement of the basis sets. According to these results, it can be said that the enlargement of the basis sets does not contribute to more accurate production of the bond parameters.

The Q values of the basis sets used with the DFT and HF method in the calculations of the nickel complex are presented comparatively in Figures 4a and b, respectively. For DFT/B3LYP method, Figure 4a indicates that the basis sets between 6-321G-LANL2DZ of which Q values fairly close to 1 are reasonably successful in reproducing the bond angles around the nickel atom, while 6-31G and 6-31G(d) gave slightly better results than the others for bond lengths around the metal atom.

For HF method, the Q values compared in Figure $4 \mathrm{~b}$ demonstrate that $3-21 \mathrm{G}$ basis set is significantly effective in production the bond angles and especially bond lengths around the metal atom according to the large basis sets. All basis sets gave similar results for other bond parameters. 


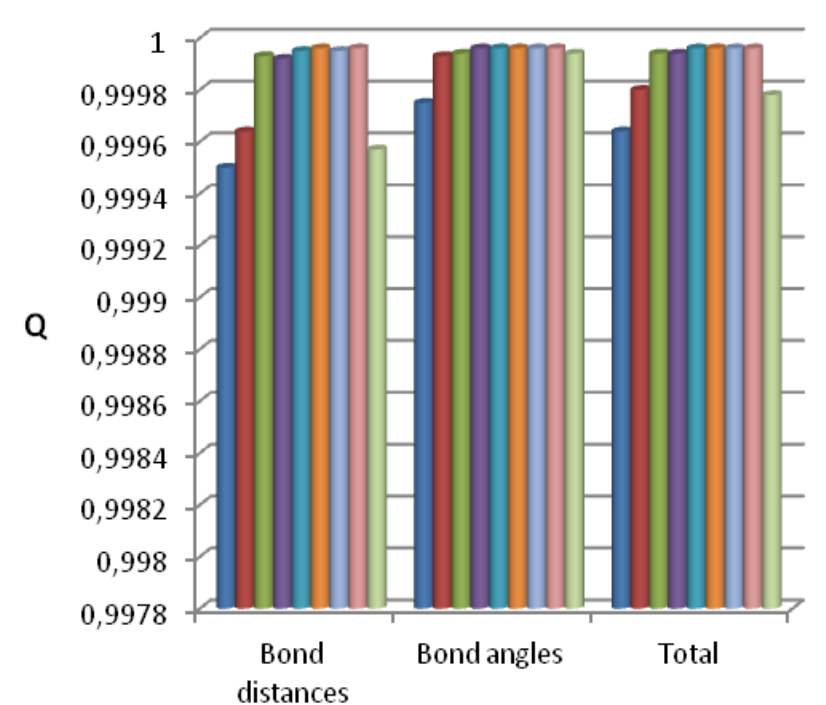

(a)

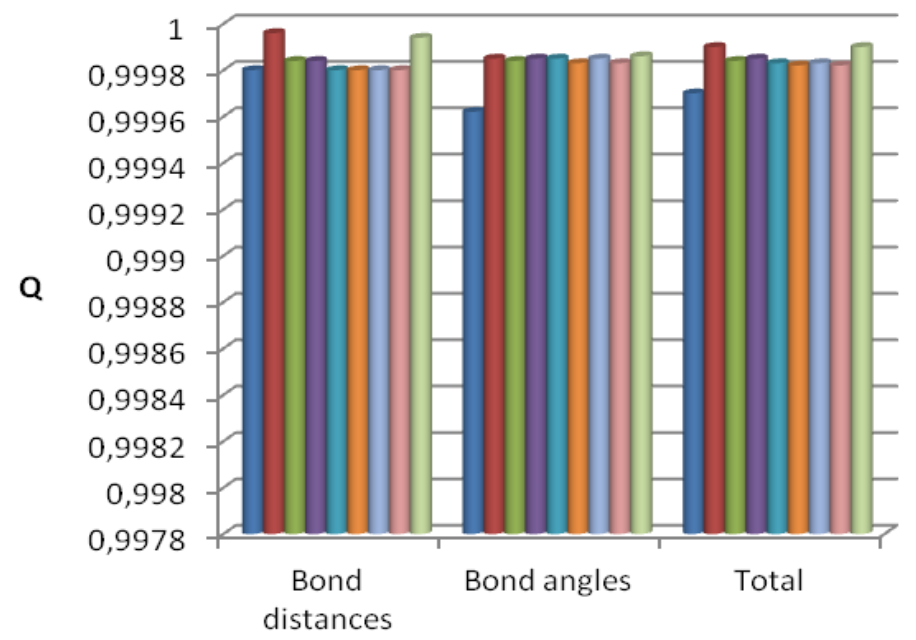

$=B 3 L Y P / 3-21 G$

B BLYP/6-31G

B $3 \mathrm{LYP} / 6-31 \mathrm{G}(\mathrm{d})$

- $B 3 \mathrm{LYP} / 6-31+\mathrm{G}(\mathrm{d})$

-B3LYP/6-311+G(d)

-B3LYP/6-311+G(2d)

$\approx \mathrm{B} 3 \mathrm{LYP} / 6-311++\mathrm{G}(\mathrm{d})$

B3LYP/6-311++G(2d)

B3LYP/LANL2DZ

(b)

Figure 3. Comprasion of the basis sets using the B3LYP method (a) and the HF method (b) for vic-dioxime ligand

For coordination compounds, bond lengths and angles around the central metal atom are of great importance. The DFT method applied with the other basis sets except 3-21G is really better in reproducing especially bond lenghts around nickel atom. than the HF method. The quality in the bond lengths around metal atom became worse with addition of d polarization and diffusion functions to the base sets after 3-21G for the HF method. In DFT and HF calculations, the enlargement in the basis sets after 6-31G didn't improve the quality in the bond angles around nickel atom.

According to total Q values of all the computational methods tested for the ligand and its $\mathrm{Ni}$ (II) complex, the DFT/B3LYP method with especially large base sets seems to be a good choice for the production of most accurate bond parameters and the reproduce $\mathrm{X}$-ray structures of vic-dioxim ligand and complex. 


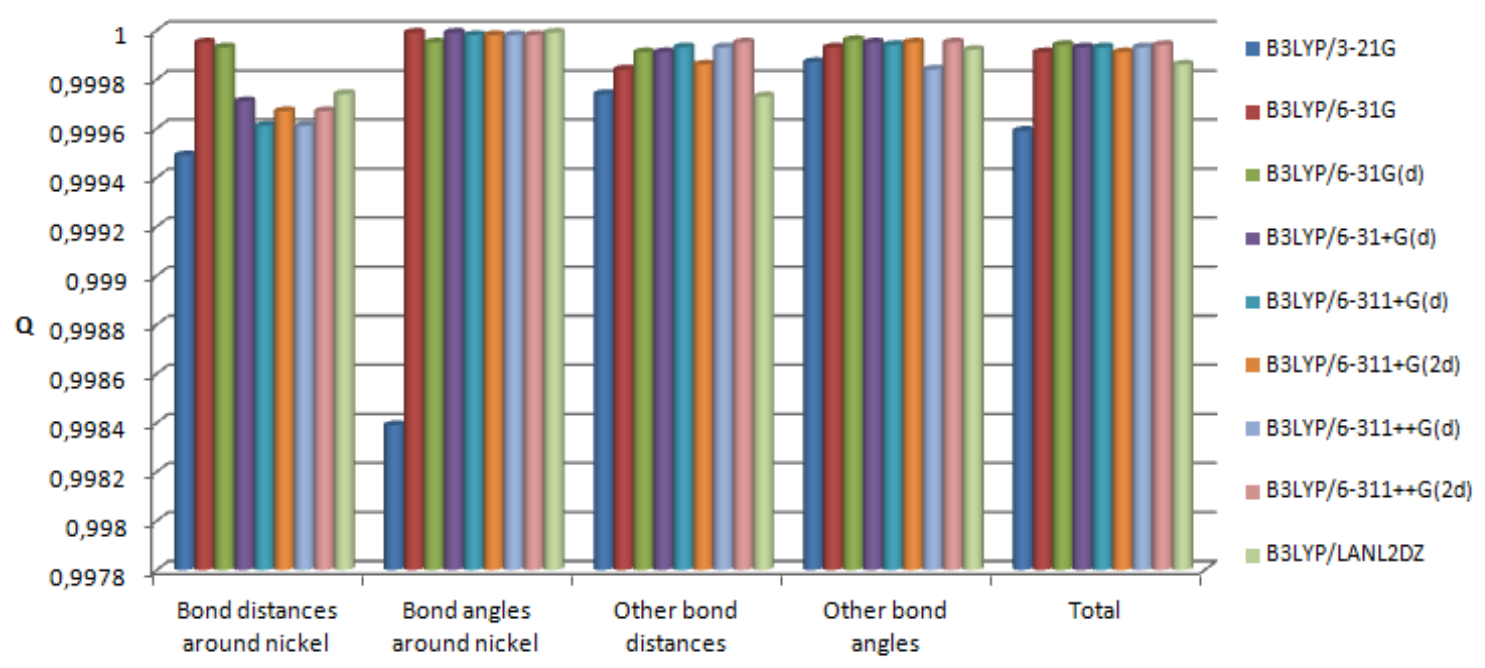

(a)

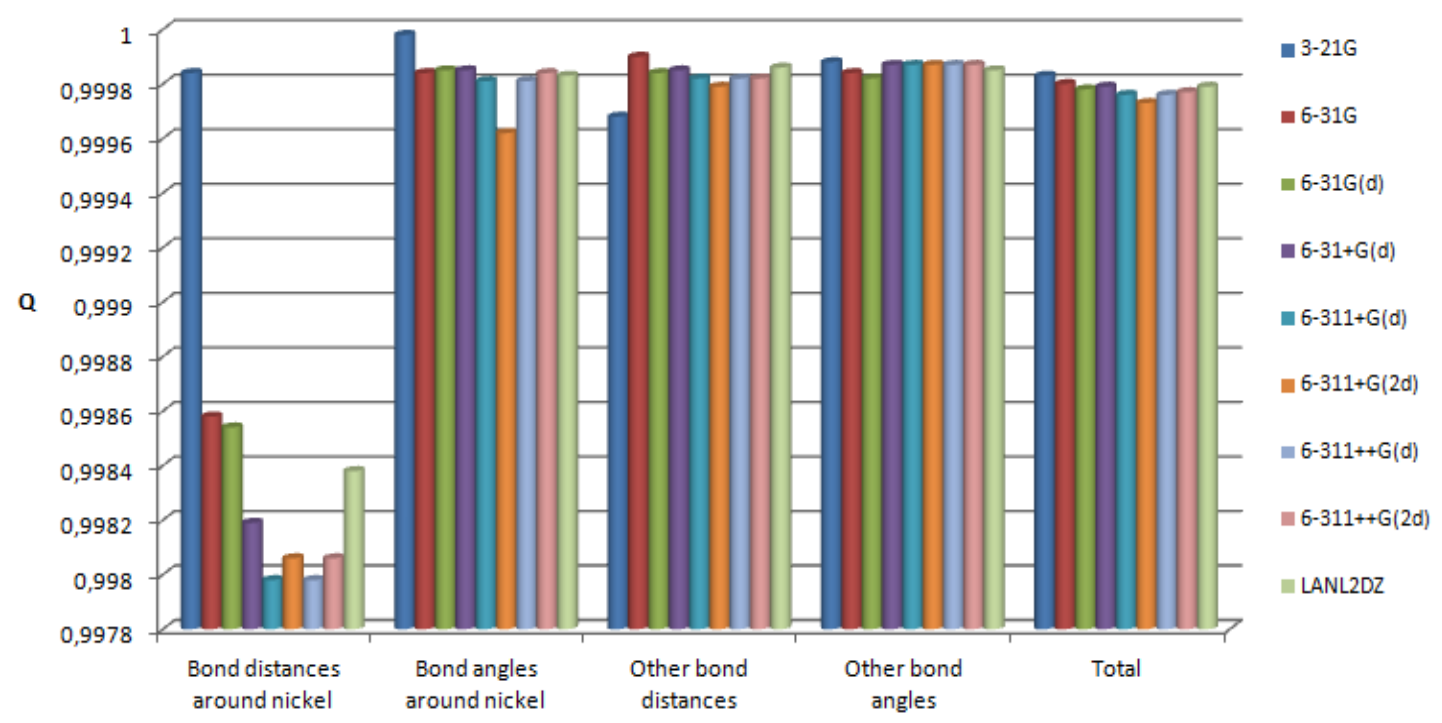

(b)

Figure 4. Comprasion of the basis sets using the B3LYP method (a) and the HF method (b) for Ni(II) complex

\section{2. ${ }^{1} \mathrm{H}$ NMR Spectroscopy}

Gauge including atomic orbital (GIAO) ${ }^{1} \mathrm{H}$ NMR chemical shift values (with respect to TMS) were computed using the DFT/B3LYP and HF methods with 6-31G(d) basis set and DFT/B3LYP method with 6-311++G(2d) basis set. Since the experimental ${ }^{1} \mathrm{H}$ NMR spectra of the ligand and its complex were recorded in deuterated dimethyl sulfoxide (DMSO-d6) solvent, the NMR spectra calculations were performed in the same solvent. The theoretical ${ }^{1} \mathrm{H}$ chemical shift values of the compounds were compared to the experimental chemical shift values. The results of these calculations are presented in Table 2.

The deuterium exchangeable protons of the $\mathrm{N}-\mathrm{H}$ and two $\mathrm{O}-\mathrm{H}$ groups of the ligand showing characteristic chemical shifts appear at a singlet at 6.96, 10.30 and $9.27 \mathrm{ppm}$, respectively in the experimental ${ }^{1} \mathrm{H}$ NMR spectra. 
The deuterium exchangeable protons of the $\mathrm{N}-\mathrm{H}$ and two $\mathrm{O}-\mathrm{H}$ groups of the ligand showing characteristic chemical shifts appear at a singlet at $6.96,10.30$ and $9.27 \mathrm{ppm}$, respectively in the experimental ${ }^{1} \mathrm{H}$ NMR spectra. These peaks were calculated as 5.60, 5.56 and $6.91 \mathrm{ppm}$ at B3LYP/6$31 \mathrm{G}(\mathrm{d})$ level, 6.16, 6.77 and 7.32 ppm at B3LYP/6-311++G(2d) level and 5.19, 4.68 and 5.81 ppm at HF/6-31G(d)level, respectively. There are big differences between the theoretical and experimental NMR shifts of ligand's OH protons. The ${ }^{1} \mathrm{H}$ NMR spectrum of the diamagnetic nickel (II) complex indicates $\mathrm{O}-\mathrm{H} \cdots \mathrm{O}$ bridge formation resulting in a strong shift of the $\mathrm{OH}$ protons to lower field (15.37 $\mathrm{ppm}$ ) compared to the free ligand [28-30]. This statement was calculated $12.38 \mathrm{ppm}$ at B3LYP/6-31G(d) level, $12.20 \mathrm{ppm}$ at B3LYP/6-311++G(2d) level and $9.86 \mathrm{ppm}$ at HF/6-31G(d)level. The multiple signals between 7.11 and $6.40 \mathrm{ppm}$ represent the aromatic protons of the phenyl groups of both ligand and its complex, and they were found in the region of 7.69-7.01 ppm for all methods, as seen in Table 2. A singlet at 1.90/1.42 ppm (ligand/Ni complex) for $\mathrm{CH}_{3}$ protons of the $\mathrm{CH}_{3}-\mathrm{C}=\mathrm{N}-$ group was found at intervals of 1.35-2.02/0.90-2.28 ppm at B3LYP/6-31G(d) level, 1.42-2.01/0.88-2.25 ppm at B3LYP/6-311++G(2d) level and 1.38-2.40/0.78-4.61 ppm at HF/6-31G(d) level. The other computed chemical shift values can be seen in Table 2.

Table 2. Theoretical and experimental ${ }^{1} \mathrm{H}$ NMR chemical shifts (ppm) for vic-dioxime ligand and its Ni (II) complex calculated at the B3LYP/6-31G(d), B3LYP/6-311++G(2d) and HF/6-31G(d)levels.

\begin{tabular}{|c|c|c|c|c|c|c|c|c|}
\hline & \multicolumn{4}{|c|}{ Ligand } & \multicolumn{4}{|c|}{ Nickel Complex } \\
\hline & $\begin{array}{l}\text { Exp. } \\
{[10]}\end{array}$ & $\begin{array}{l}\text { B3LYP/ } \\
6-31 G(d)\end{array}$ & $\begin{array}{c}\text { B3LYP/ } \\
6-311++G(2 d)\end{array}$ & $\begin{array}{c}\mathrm{HF} / \\
6-31 \mathrm{G}(\mathrm{d})\end{array}$ & $\begin{array}{l}\text { Exp. } \\
{[10]}\end{array}$ & $\begin{array}{l}\text { B3LYP/ } \\
6-31 G(d)\end{array}$ & $\begin{array}{c}\text { B3LYP/ } \\
6-311++G(2 d)\end{array}$ & $\begin{array}{c}\mathrm{HF} / \\
6-31 \mathrm{G}(\mathrm{d})\end{array}$ \\
\hline $\mathrm{O} 1-\mathrm{H}-\mathrm{O} 2^{\mathrm{i}}$ & - & - & - & - & $15.37 \mathrm{~s}$ & 12.38 & 12.20 & 9.86 \\
\hline $\mathrm{O}{ }^{\mathrm{i}}-\mathrm{H}^{-} \mathrm{O} 2$ & - & - & - & - & $15.37 \mathrm{~s}$ & 12.38 & 12.20 & 9.86 \\
\hline $\mathrm{O} 1-\mathrm{H}$ & $10.30 \mathrm{~s}$ & 5.56 & 6.77 & 4.68 & - & - & - & - \\
\hline $\mathrm{O} 2-\mathrm{H}$ & $9.27 \mathrm{~s}$ & 6.91 & 7.32 & 5.81 & - & - & - & - \\
\hline N1-H & 6.96 & 5.60 & 6.16 & 5.19 & $8.59 \mathrm{~s}$ & 5.34 & 6.42 & 5.34 \\
\hline $\mathrm{N} 1{ }^{\mathrm{i}}-\mathrm{H}$ & - & - & - & - & $8.59 \mathrm{~s}$ & 5.34 & 6.42 & 5.34 \\
\hline C3-H & $\begin{array}{c}6.64- \\
6.40 \mathrm{~m} \\
\end{array}$ & 7.01 & 7.33 & 7.35 & $\begin{array}{c}7.11- \\
7.09 \mathrm{~m} \\
\end{array}$ & 7.10 & 7.39 & 7.36 \\
\hline $\mathrm{C} 3^{\mathrm{i}}-\mathrm{H}$ & - & - & - & - & $\begin{array}{c}7.11- \\
7.09 \mathrm{~m}\end{array}$ & 7.10 & 7.39 & 7.36 \\
\hline $\mathrm{C} 4-\mathrm{H}$ & $\begin{array}{c}6.64- \\
6.40 \mathrm{~m} \\
\end{array}$ & 7.10 & 7.37 & 7.61 & $\begin{array}{c}7.11- \\
7.09 \mathrm{~m}\end{array}$ & 7.17 & 7.43 & 7.69 \\
\hline $\mathrm{C} 4^{\mathrm{i}}-\mathrm{H}$ & - & - & - & - & $\begin{array}{c}7.11- \\
7.09 \mathrm{~m}\end{array}$ & 7.17 & 7.43 & 7.17 \\
\hline $\mathrm{C} 5-\mathrm{H}$ & $\begin{array}{c}6.64- \\
6.40 \mathrm{~m} \\
\end{array}$ & 7.10 & 7.43 & 7.42 & $\begin{array}{c}7.11- \\
7.09 \mathrm{~m} \\
\end{array}$ & 7.14 & 7.43 & 7.36 \\
\hline $\mathrm{C} 5^{\mathrm{i}}-\mathrm{H}$ & - & - & - & - & $\begin{array}{c}7.11- \\
7.09 \mathrm{~m}\end{array}$ & 7.14 & 7.43 & 7.36 \\
\hline $\mathrm{C} 11-\mathrm{H}_{\mathrm{A}}$ & $1.90 \mathrm{~s}$ & 1.35 & 1.42 & 1.38 & $1.42 \mathrm{~s}$ & 0.90 & 0.88 & 0.78 \\
\hline $\mathrm{C} 11-\mathrm{H}_{\mathrm{B}}$ & $1.90 \mathrm{~s}$ & 1.57 & 1.54 & 1.65 & $1.42 \mathrm{~s}$ & 1.03 & 1.02 & 0.78 \\
\hline C11-Hc & $1.90 \mathrm{~s}$ & 2.02 & 2.01 & 2.40 & $1.42 \mathrm{~s}$ & 2.28 & 2.25 & 4.61 \\
\hline $\mathrm{C} 11^{\mathrm{i}}-\mathrm{H}_{\mathrm{A}}$ & - & - & - & - & $1.42 \mathrm{~s}$ & 0.90 & 0.88 & 0.78 \\
\hline $\mathrm{C} 11^{\mathrm{i}}-\mathrm{H}_{\mathrm{B}}$ & - & - & - & - & $1.42 \mathrm{~s}$ & 1.03 & 1.02 & 0.78 \\
\hline $\mathrm{C} 11^{\mathrm{i}}-\mathrm{H}_{\mathrm{C}}$ & - & - & - & - & $1.42 \mathrm{~s}$ & 2.28 & 2.25 & 4.61 \\
\hline $\mathrm{C} 7-\mathrm{H}_{\mathrm{A}}$ & $2.10 \mathrm{~s}$ & 1.98 & 2.28 & 2.06 & $2.20 \mathrm{~s}$ & 1.98 & 2.21 & 1.94 \\
\hline C7-HB & $2.10 \mathrm{~s}$ & 2.30 & 2.51 & 2.49 & $2.20 \mathrm{~s}$ & 2.33 & 2.53 & 2.13 \\
\hline $\mathrm{C} 7-\mathrm{H}_{\mathrm{C}}$ & $2.10 \mathrm{~s}$ & 2.57 & 2.72 & 2.66 & $2.20 \mathrm{~s}$ & 2.51 & 2.57 & 1.99 \\
\hline $\mathrm{C}^{\mathrm{i}}-\mathrm{H}_{\mathrm{A}}$ & - & - & - & - & $2.20 \mathrm{~s}$ & 1.98 & 2.21 & 1.94 \\
\hline $\mathrm{C}^{\mathrm{i}}-\mathrm{H}_{\mathrm{B}}$ & - & - & - & - & $2.20 \mathrm{~s}$ & 2.33 & 2.53 & 2.13 \\
\hline $\mathrm{C}^{\mathrm{i}}-\mathrm{H}_{\mathrm{C}}$ & - & - & - & - & $2.20 \mathrm{~s}$ & 2.51 & 2.57 & 1.99 \\
\hline $\mathrm{C} 8-\mathrm{H}_{\mathrm{A}}$ & $2.10 \mathrm{~s}$ & 1.79 & 2.06 & 1.20 & $2.20 \mathrm{~s}$ & 2.02 & 2.19 & 1.94 \\
\hline $\mathrm{C} 8-\mathrm{H}_{\mathrm{B}}$ & $2.10 \mathrm{~s}$ & 2.16 & 2.32 & 2.24 & $2.20 \mathrm{~s}$ & 2.18 & 2.32 & 1.99 \\
\hline $\mathrm{C} 8-\mathrm{H}_{\mathrm{C}}$ & $2.10 \mathrm{~s}$ & 2.42 & 2.63 & 2.42 & $2.20 \mathrm{~s}$ & 2.31 & 2.47 & 2.13 \\
\hline $\mathrm{C}^{\mathrm{i}}-\mathrm{H}_{\mathrm{A}}$ & - & - & - & - & $2.20 \mathrm{~s}$ & 2.02 & 2.19 & 1.94 \\
\hline $\mathrm{C}^{\mathrm{i}}-\mathrm{H}_{\mathrm{B}}$ & - & - & - & - & $2.20 \mathrm{~s}$ & 2.18 & 2.32 & 1.99 \\
\hline $\mathrm{C}^{\mathrm{i}}-\mathrm{H}_{\mathrm{C}}$ & - & - & - & - & $2.20 \mathrm{~s}$ & 2.31 & 2.47 & 2.13 \\
\hline
\end{tabular}


As can be seen from Table 2, the theoretical ${ }^{1} \mathrm{H}$ chemical shift values obtained by the DFT methods at the GIAO/B3LYP/6-31G(d) and 6-311++G(2d) levels are similar to each other, and the these results of both methods are, in general, closer to the experimental ${ }^{1} \mathrm{H}$ shift data than the results obtained by the HF method at the 6-31G(d) level.

\subsection{IR Spectroscopy}

Harmonic vibrational frequencies of the ligand and its complex were calculated by using DFT/B3LYP method with 6-31G(d), 6-311++G(2d) basis sets and HF method with 6-31G(d) basis set. Some primary calculated vibrational frequencies identified by using Gauss-View molecular visualization program are summarized in Table 3 and compared the experimental data. As can be seen from Table 3, there are some discrepancy between theoretical and experimental frequencies values. These differences arise from the fact that the experimental spectra of the compounds have been recorded in the solid phase, whereas the theoretical IR spectra have been calculated in the gas phase in which the molecules are isolated. In addition to this, the experimental values are anharmonic vibrations, in contrast, the computed frequencies correspond to harmonic vibrations [31].

In the experimental IR spectrum of the ligand, the strong $v(\mathrm{OH}), v(\mathrm{NH}), v(\mathrm{C}=\mathrm{N})$ and $v(\mathrm{NO})$ characteristic stretching vibrations bands were observed at $3457,3380,1648$ and $963 \mathrm{~cm}^{-1}$, respectively. The calculated bands due to these stretchings were found to be 3779/3756, 3340, 1719/1675 and $1046 / 977 / 945 \mathrm{~cm}^{-1}$ at the DFT/B3LYP/6-31G(d) level, 3809/3789, 3565, 1706/1657 and 1037/960/934 at the DFT/B3LYP/6-311++G(2d) level and 4143/4129, 3832, 1962/1933 and 1182/1108/1067 at HF/6$31 \mathrm{G}(\mathrm{d})$. The experimental FT-IR spectra of the complex displayed a weak deformation band at 1807 $\mathrm{cm}^{-1}$ together with the disappearance of $(\mathrm{O}-\mathrm{H})$ stretching band in the IR spectrum of free ligand. This band is indicative of the intramolecular hydrogen-bonded bending vibrations $(\mathrm{O}-\mathrm{H} \cdots \mathrm{O})$ and was calculated $1744 \mathrm{~cm}^{-1}$ at the B3LYP/6-31G(d) level, 1727 at the B3LYP/6-311++G(2d) level and 1885 at $\mathrm{HF} / 6-31 \mathrm{G}(\mathrm{d})$.

Table 3. Theoretical and experimental vibrational frequencies for vic-dioxime ligand and its $\mathrm{Ni}(\mathrm{II})$ complex calculated at the B3LYP/6-31G(d), B3LYP/6-311++G(2d) and HF/6-31G(d) levels.

\begin{tabular}{|c|c|c|c|c|c|c|c|c|}
\hline \multirow[b]{2}{*}{ Assigments $^{\mathrm{a}}$} & \multicolumn{4}{|c|}{ Ligand } & \multicolumn{4}{|c|}{ Nickel Complex } \\
\hline & $\begin{array}{l}\text { Exp. } \\
{[10]}\end{array}$ & $\begin{array}{l}\text { B3LYP/ } \\
6-31 G(d)\end{array}$ & $\begin{array}{c}\text { B3LYP/ } \\
6-311++G(2 d)\end{array}$ & $\begin{array}{c}\mathrm{HF} / \\
6-31 \mathrm{G}(\mathrm{d})\end{array}$ & $\begin{array}{l}\text { Exp. } \\
{[10]}\end{array}$ & $\begin{array}{l}\text { B3LYP/ } \\
6-31 G(d)\end{array}$ & $\begin{array}{c}\text { B3LYP/ } \\
6-311++G(2 d)\end{array}$ & $\begin{array}{c}\mathrm{HF} / \\
6-31 \mathrm{G}(\mathrm{d})\end{array}$ \\
\hline$v(\mathrm{O}-\mathrm{H})$ & 3457 & $\begin{array}{l}3779 \\
3756 \\
\end{array}$ & $\begin{array}{l}3809 \\
3789 \\
\end{array}$ & $\begin{array}{l}4143 \\
4129 \\
\end{array}$ & - & - & - & 3635 \\
\hline$v(\mathrm{~N}-\mathrm{H})$ & 3380 & 3567 & 3565 & 3832 & 3315 & 3543 & 3530 & 3815 \\
\hline$v_{s}(\mathrm{CH})$ phe. & 3206 & 3203 & 3165 & 3382 & 3081 & 3206 & 3167 & 3385 \\
\hline$v_{a s}(\mathrm{CH})_{\text {phe. }}$ & 3098 & $\begin{array}{l}3185- \\
3177 \\
\end{array}$ & 3147 & 3366 & 3019 & 3189 & 3149 & 3370 \\
\hline vas $\left(\mathrm{CH}_{3}\right)$ & 2956 & $\begin{array}{l}3135- \\
3113 \\
\end{array}$ & $\begin{array}{l}3140- \\
3068\end{array}$ & $\begin{array}{l}3326- \\
3274\end{array}$ & 2955 & $\begin{array}{l}3161- \\
3099\end{array}$ & $\begin{array}{l}3130- \\
3067\end{array}$ & $\begin{array}{l}336- \\
3268\end{array}$ \\
\hline$v_{s}\left(\mathrm{CH}_{3}\right)$ & 2859 & $\begin{array}{l}3101- \\
3042 \\
\end{array}$ & $\begin{array}{l}3042- \\
3020 \\
\end{array}$ & $\begin{array}{l}3229- \\
3217 \\
\end{array}$ & 2855 & $\begin{array}{l}3052- \\
3044 \\
\end{array}$ & $\begin{array}{l}3029- \\
3023 \\
\end{array}$ & $\begin{array}{l}3229- \\
3212 \\
\end{array}$ \\
\hline$v(\mathrm{O}-\mathrm{H} \cdots \mathrm{O})$ & - & - & - & - & $\begin{array}{l}2430- \\
2354\end{array}$ & 2754 & 2809 & - \\
\hline$\delta(\mathrm{O}-\mathrm{H} \cdots \mathrm{O})$ & - & - & - & - & 1807 & 1744 & 1727 & 1885 \\
\hline $\begin{array}{l}v(\mathrm{C}=\mathrm{N})+ \\
\delta(\mathrm{O}-\mathrm{H} \cdots \mathrm{O}) \\
+\gamma(\mathrm{N}-\mathrm{H})\end{array}$ & 1648 & $\begin{array}{l}1719 \\
1675\end{array}$ & $\begin{array}{l}1706 \\
1657\end{array}$ & $\begin{array}{l}1962 \\
1933\end{array}$ & 1590 & $\begin{array}{l}1631 \\
1566\end{array}$ & $\begin{array}{l}1612 \\
1549\end{array}$ & $\begin{array}{l}1752 \\
1741\end{array}$ \\
\hline $\begin{array}{l}v(\mathrm{~N}-\mathrm{O})+ \\
\omega\left(\mathrm{CH}_{3}\right)\end{array}$ & 963 & $\begin{array}{l}1046 \\
977 \\
945\end{array}$ & $\begin{array}{c}1037 \\
960 \\
934 \\
\end{array}$ & $\begin{array}{l}1182 \\
1108 \\
1067 \\
\end{array}$ & 989 & $\begin{array}{l}1335 \\
1223 \\
1113 \\
\end{array}$ & $\begin{array}{l}1304 \\
1205 \\
1103\end{array}$ & $\begin{array}{l}1406 \\
1315 \\
1228 \\
\end{array}$ \\
\hline
\end{tabular}

${ }^{\mathrm{a}}, v$, stretching; $\delta$, bending vibration; $\gamma$ rocking; $\omega$, wagging; s, symmetric; as, asymmetric. 
For the complex, the calculated bands at $1631 / 1566,1612 / 1549$ and $1752 / 1741 \mathrm{~cm}^{-1}$ were assigned to the stretching vibrations of $\mathrm{C}=\mathrm{N}$ groups bound to the metal ion for the B3LYP/6-31G(d), B3LYP/6$311++\mathrm{G}(2 \mathrm{~d})$ and $\mathrm{HF} / 6-31 \mathrm{G}(\mathrm{d})$.levels, respectively. The experimental $v(\mathrm{C}=\mathrm{N})$ vibration was appeared at $1590 \mathrm{~cm}^{-1}$ in FT-IR. The experimental N-H and N-O stretching modes were observed at 3315 and 989 $\mathrm{cm}^{-1}$ and these were calculated at the region of $3530-3818$ and $1406-1103 \mathrm{~cm}^{-1}$ for all methods. As seen from Table 3, the DFT levels used in this work produce results close to both each other and experimental data.

\subsection{Electronic Absorption Spectra}

In previous publication, the experimental UV-Vis spectrums of the ligand and its $\mathrm{Ni}(\mathrm{II})$ complex had been recorded in the dimethyl sulfoxide (DMSO) solvent [10]. In this study, the electronic absorption spectra of the compounds in the same solvation were calculated using the time-dependent DFT (TDDFT) method with the B3LYP/6-31G(d) level by applying the polarizable continuum model (PCM). The major contributions of the transitions were analyzed using the Swizard program [32].

The calculated excited states, transition wavelengths $(\lambda)$, oscillator strengths are given in Table 4 together with experimental results. Since theoretical and experimental results are not consistent for the HF theory, only calculated data using the DFT are given in this section.

The molecular orbital surfaces and energy levels of the ligand and complex are shown in Figure 5 (a) and Figure 5 (b), respectively.

Table 4. Experimental and calculated electronic transitions, oscillator strengths and their assignments for vicdioxime ligand and its $\mathrm{Ni}(\mathrm{II})$ complex $^{\mathrm{a}}$

\begin{tabular}{|c|c|c|c|c|c|}
\hline $\begin{array}{c}\operatorname{Exp}(\mathbf{n m})\left(\lambda_{\max }\right) \\
{[10]}\end{array}$ & $\begin{array}{l}\text { Calcd. } \\
(\mathbf{n m})\end{array}$ & $\begin{array}{l}\text { Osc. } \\
\text { strength }\end{array}$ & & Major contributions & \\
\hline \multicolumn{6}{|l|}{ Ligand } \\
\hline 290 & 281 & 0.124 & $\mathrm{H} \rightarrow \mathrm{L}(94 \%)$ & & \\
\hline \multirow[t]{4}{*}{244} & 252 & 0.043 & $\mathrm{H} \rightarrow \mathrm{L}+1(69 \%)$ & & \\
\hline & 248 & 0.035 & $\mathrm{H}-1 \rightarrow \mathrm{L}(41 \%)$ & $\mathrm{H} \rightarrow \mathrm{L}+1(23 \%)$ & \\
\hline & 239.0 & 0.018 & $\mathrm{H} \rightarrow \mathrm{L}+2(51 \%)$ & $\mathrm{H}-1 \rightarrow \mathrm{L}(33 \%)$ & $\mathrm{H}-1 \rightarrow \mathrm{L}+1(11 \%)$ \\
\hline & 236 & 0.062 & $\mathrm{H}-2 \rightarrow \mathrm{L}(83 \%)$ & & \\
\hline \multirow[t]{5}{*}{221} & 222 & 0.042 & $\mathrm{H}-4 \rightarrow \mathrm{L}(27 \%)$ & $\mathrm{H}-1 \rightarrow \mathrm{L}+1(23 \%)$ & \\
\hline & 220 & 0.019 & $\mathrm{H}-4 \rightarrow \mathrm{L}(+26 \%)$ & $\mathrm{H}-2 \rightarrow \mathrm{L}+2(12 \%)$ & \\
\hline & 212 & 0.093 & $\mathrm{H}-3 \rightarrow \mathrm{L}(34 \%)$ & $\mathrm{H}-2 \rightarrow \mathrm{L}(7 \%)$ & \\
\hline & 210 & 0.017 & $\mathrm{H}-5 \rightarrow \mathrm{L}(32 \%)$ & $\mathrm{H}-3 \rightarrow \mathrm{L}(31 \%)$ & $\mathrm{H}-4 \rightarrow \mathrm{L}(15 \%)$ \\
\hline & 203 & 0.055 & $\mathrm{H}-2 \rightarrow \mathrm{L}+1(39 \%)$ & $\mathrm{H}-1 \rightarrow \mathrm{L}+2(33 \%)$ & $\mathrm{H}-3 \rightarrow \mathrm{L}+0(+12 \%)$ \\
\hline \multicolumn{6}{|l|}{ Nickel Complex } \\
\hline 538 & 477 & 0.045 & $\mathrm{H} \rightarrow \mathrm{L}(96 \%)$ & & \\
\hline 444 & 383 & 0.008 & $\mathrm{H}-3 \rightarrow \mathrm{L}(93 \%)$ & & \\
\hline \multirow[t]{2}{*}{356} & 369 & 0.009 & $\mathrm{H}-1 \rightarrow \mathrm{L}+1(76 \%)$ & $\mathrm{H}-1 \rightarrow \mathrm{L}+2(16 \%)$ & \\
\hline & 348 & 0.435 & $\mathrm{H}-2 \rightarrow \mathrm{L}(84 \%)$ & & \\
\hline \multirow[t]{2}{*}{314} & 319 & 0.036 & $\mathrm{H}-5 \rightarrow \mathrm{L}+1(34 \%)$ & $\mathrm{H}-11 \rightarrow \mathrm{L}(29 \%)$ & \\
\hline & 307 & 0.012 & $\mathrm{H}-1 \rightarrow \mathrm{L}+2(57 \%)$ & $\mathrm{H}-9 \rightarrow \mathrm{L}(26 \%)$ & \\
\hline \multirow[t]{3}{*}{274} & 295 & 0.080 & H-6 $\rightarrow$ L $(30 \%)$ & $\mathrm{H}-11 \rightarrow \mathrm{L}(21 \%)$ & \\
\hline & 293 & 0.055 & $\mathrm{H}-6 \rightarrow \mathrm{L}(62 \%)$ & $\mathrm{H}-8 \rightarrow \mathrm{L}(9 \%)$ & \\
\hline & 290 & 0.028 & $\mathrm{H}-8 \rightarrow \mathrm{L}(63 \%)$ & $\mathrm{H}-12 \rightarrow \mathrm{L}(9 \%)$ & \\
\hline
\end{tabular}

${ }^{\mathrm{a}} \mathrm{H}$ : highest occupied molecular orbital (HOMO), L: lowest unoccupied molecular orbital (LUMO)

In the ligand, the vic-dioxime group plays an important role in HOMO (\%52), HOMO-2 (\%44), HOMO3 (\%68), HOMO-4 (\%90), HOMO-5 (\%87) and LUMO (\%72) molecular orbitals while HOMO-1 (\%87), HOMO-2 (\%51), LUMO+1 (\%73) and LUMO+2 (\%81) orbitals are delocalized on the phenyl ring. The three absorption bands in the experimental spectrum of the ligand were observed at around 
$221-290 \mathrm{~nm}$. The absorption at $290 \mathrm{~nm}$ is contributed by the electron excitation from HOMO to LUMO at $281 \mathrm{~nm}$. The bands observed at 244 and $221 \mathrm{~nm}$ were calculated at 252,222 nm. All these transitions can be attributed to the $\pi \rightarrow \pi^{*}$ transitions [33].

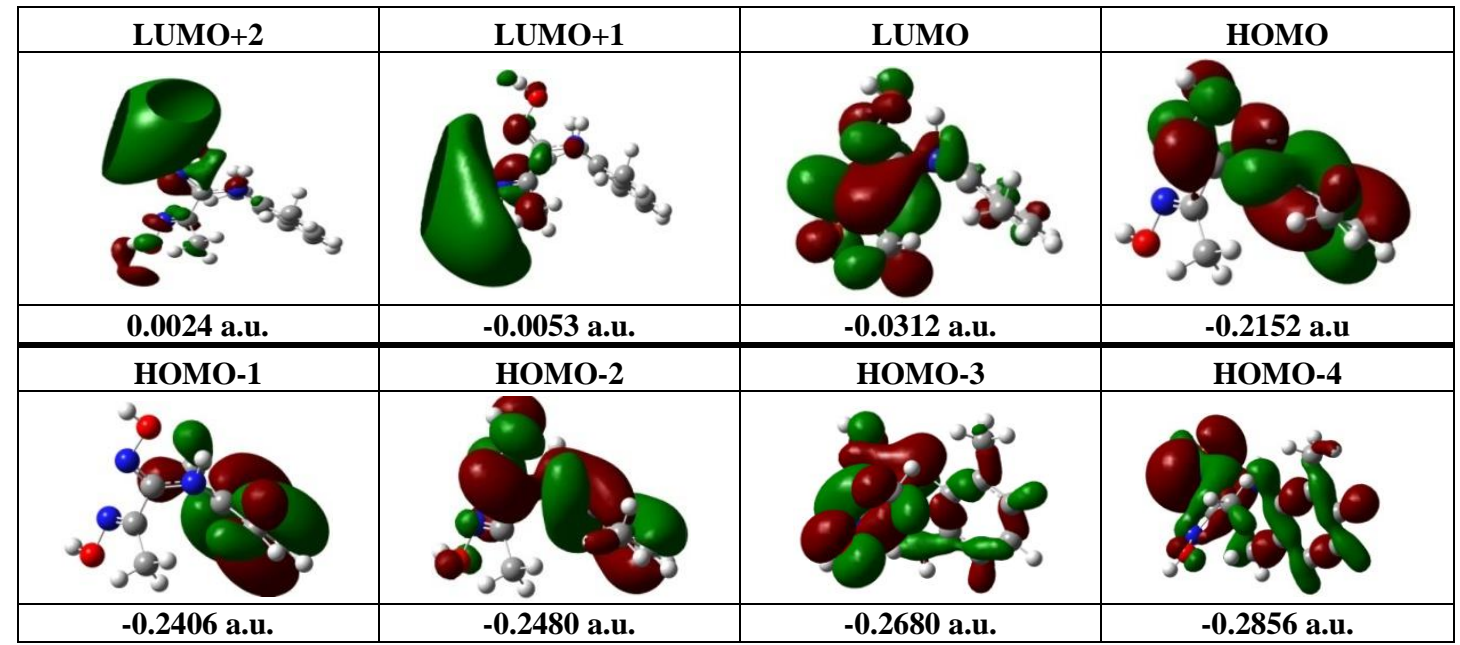

(a)

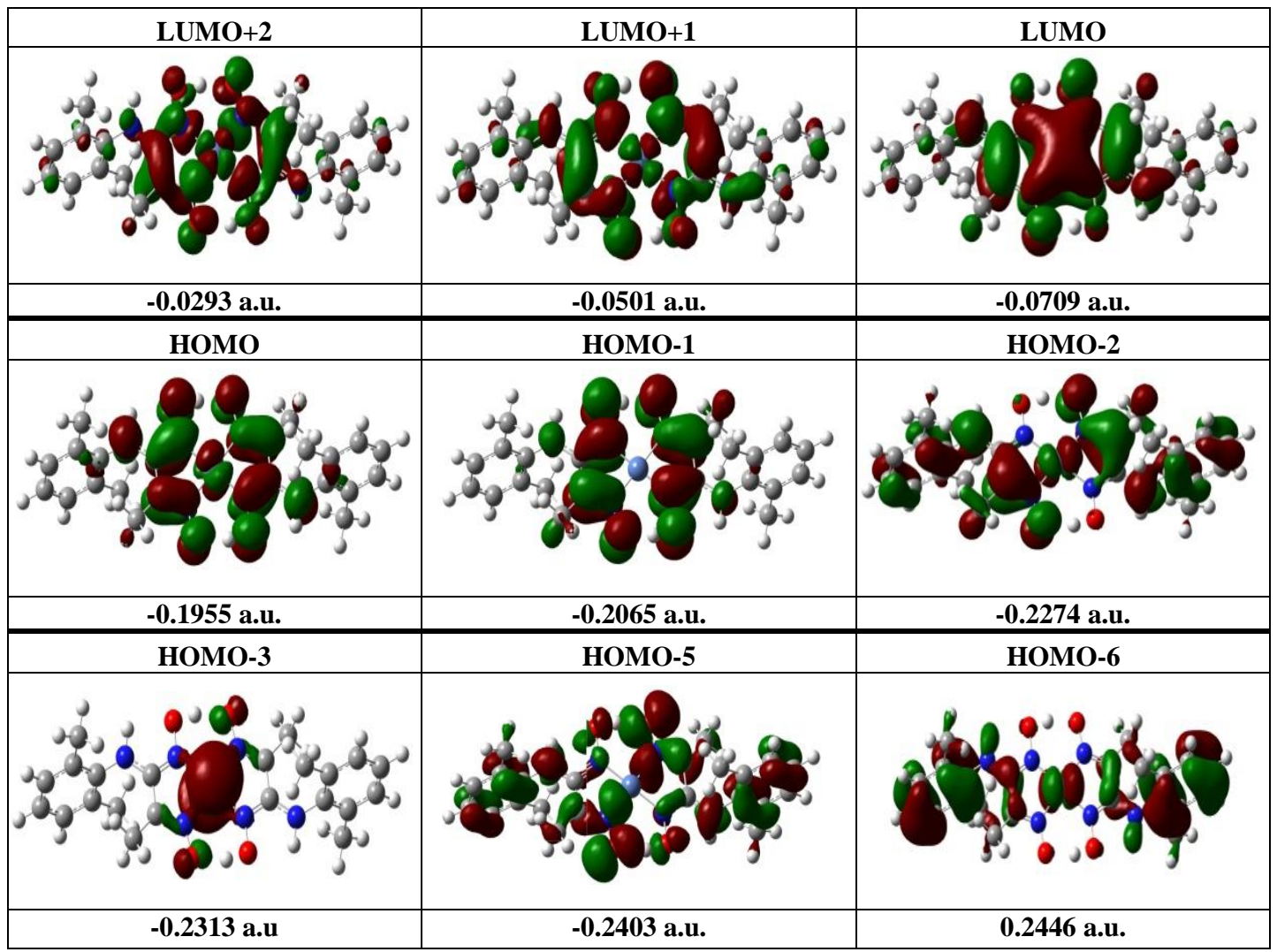

(b)

Figure 5. Some molecular orbital surfaces and energy levels using for the vic-dioxime ligand (a) and its $\mathrm{Ni}$ (II) complex (b). (Green and red represent the positive and negative isosurfaces of molecular orbitals, respectively)

In the nickel complex, LUMO, LUMO+1 and LUMO+2 are constructed from the d-orbitals of nickel atom $(5,22,27 \%)$, the p orbitals of vic-dioxime $(78,66,58 \%)$, phenyl $(5,5,4 \%)$ and other groups $(12$, 8, 10\%). HOMO, HOMO-1, HOMO-2, HOMO-3, HOMO-5, HOMO-9, HOMO-11, HOMO-12 have $64,91,39,11,74,27,77,43 \%$ contrubition of vic-dioxime $\mathrm{p}$ orbitals. The contributions of nickel d 
orbitals to the same molecular orbitals are $23,0,24,88,2,70,20,40 \%$, respectively. HOMO- 8 essentially consist of $\pi$ orbitals of phenyl group (52\%) and the d-orbitals of metal (29\%) while HOMO6 is composed of $86 \% \pi$ orbitals of phenyl group. Experimentally, the absorptions at 538 (calcd. 477 $\mathrm{nm}$ ) and $444 \mathrm{~nm}$ (calcd. $383 \mathrm{~nm}$ ) attributed to HOMO $\rightarrow$ LUMO (\%96) and HOMO-3 $\rightarrow$ LUMO (\%93) transitions, respectively. These absorptions can be ascribed to the MLCT (metal to ligand charge transfer) transitions. The bands at $356 \mathrm{~nm}$ (calcd. $369 \mathrm{~nm}$ ), $314 \mathrm{~nm}$ (calcd. $319 \mathrm{~nm}$ ) and $274 \mathrm{~nm}$ (calcd. $295 \mathrm{~nm}$ ) may be assigned mainly to LLCT (ligand to ligand charge transfer) transitions (see Table 4 for the details).

\section{5 .The Natural Bond Orbital (NBO) Analysis}

The Natural Bond Orbital (NBO) analysis is a helpful tool to investigate the electrons movement between ligand and metal atom [34]. The attractive metal-ligands interactions were studied based upon natural atomic charges and the computed second-order perturbation energies [14]. Charges on all atoms of the ligand and its complex were calculated from natural population analysis (NPA) and are listed in Table 5. This donor-acceptor interaction between $\mathrm{Ni}$ and the ligands in the complex were quantitatively described by using the interaction stabilization energy $\left(\mathrm{E}^{(2)}\right)$ which resulted from the second order perturbation theory analysis of Fock matrix in NBO basis (see Table 6).

Table 5. Selected natural atomic charges (e) for the vic-dioxime ligand and its $\mathrm{Ni}$ (II) complex

\begin{tabular}{lll}
\hline Atom & Ligand & Ni Complex \\
\hline $\mathrm{Ni}$ & - & 0.77026 \\
\hline $\mathrm{N} 1\left(\mathrm{~N} 1^{\mathrm{i}}\right)$ & -0.66020 & -0.63427 \\
\hline $\mathrm{N} 2\left(\mathrm{~N} 2^{\mathrm{i}}\right)$ & -0.19778 & -0.26306 \\
\hline $\mathrm{N} 3\left(\mathrm{~N} 3^{\mathrm{i}}\right)$ & -0.12567 & -0.09145 \\
\hline $\mathrm{O} 1\left(\mathrm{O} 1^{\mathrm{i}}\right)$ & -0.60439 & -0.62504 \\
\hline $\mathrm{O} 2\left(\mathrm{O} 2^{\mathrm{i}}\right)$ & 0.58322 & -0.53030 \\
\hline
\end{tabular}

As can also be seen from natural atomic charges in the table 5, the binding sites of the vic-dioxime ligand are favorably $\mathrm{N}$ atoms of the oxime groups. The charges on the N1(amine) atoms in both the complex and the free ligand are close to each other. The difference between the charge of the N3 (oxime) atom in the complex and in the free ligand can be taken into account as an approximation of the charge transfer from the N3 atom to metal. But N2 (oxime) atom coordinated to nickel atom in the complex has a greater amount of negative charge than its charge in the ligand. The reason of this may be the increase density of electrons on $\mathrm{N} 2=\mathrm{C} 9$ oxime group together with the interaction of LP N1(amine) $\rightarrow \mathrm{N} 2=\mathrm{C} 9$ (oxime) $\left[\mathrm{E}^{(2)}=99.81 \mathrm{kcal} / \mathrm{mol}\right]$. The computed natural charge on the $\mathrm{Ni}$ atom in the complex is equal to 0.77026 $e$ and less than +2 required for $\mathrm{Ni}^{+2}$. This indicates stronger donating from ligands in the nickel complex.

In the complex, the donor-acceptor interactions between $\mathrm{Ni}^{+2}$ and the ligands are as follows:

a) $\sigma$ donation from lone pairs (LP) of $\mathrm{N}$ (oxime) atoms to unfilled $\mathrm{p}$ and d valence orbitals of $\mathrm{Ni}^{+2}$

b) donation from the $\mathrm{N}=\mathrm{C}$ (oxime) and $\mathrm{N}=\mathrm{O}$ (oxime) bonding orbitals to unfilled s and d valence orbitals of $\mathrm{Ni}^{+2}$

c) back- donation from occupied d orbitals of $\mathrm{Ni}^{+2}$ to anti-bonding orbitals of the $\mathrm{N}=\mathrm{C}$ (oxime) and $\mathrm{N}=\mathrm{O}$ (oxime) bonds

The major component of the charge transfer interactions is $\sigma$-donation from the lone pairs of $\mathrm{N}$ (oxime) atoms. As can be seen from Table 6, this interactions is larger than the $\mathrm{N}=\mathrm{C}$ (oxime) $\rightarrow \mathrm{Ni}$ and $\mathrm{N}-\mathrm{O}$ (oxime) $\rightarrow \mathrm{Ni}$ donations. The calculated second-order perturbation energies demonstrate the lesser importance of $\mathrm{Ni} \rightarrow$ ligand back donation in the vic-dioxime nickel complex. 
Table 6. The computed charge transfer interactions in the vic-dioxime Ni(II) complex

\begin{tabular}{ll}
\hline & $\mathrm{E}^{(2)}(\mathrm{kcal} / \mathrm{mol})$ \\
\hline $\mathrm{N} 2-\mathrm{O} 1$ (oxime) $\rightarrow \mathrm{Ni}$ & 1.71 \\
\hline $\mathrm{N} 3-\mathrm{O} 2$ (oxime) $\rightarrow \mathrm{Ni}$ & 2.00 \\
\hline $\mathrm{N} 2=\mathrm{C} 9($ oxime $) \rightarrow \mathrm{Ni}$ & 4.48 \\
\hline $\mathrm{N} 3=\mathrm{C} 10($ oxime $) \rightarrow \mathrm{Ni}$ & 3.95 \\
\hline $\mathrm{LP}$ N2(oxime) $\rightarrow \mathrm{Ni}$ & 68.73 \\
\hline $\mathrm{LP} \mathrm{N} 3($ oxime$) \rightarrow \mathrm{Ni}$ & 54.75 \\
\hline $\mathrm{LP} \mathrm{Ni} \rightarrow \mathrm{N} 2=\mathrm{C} 9($ oxime$)$ & 1.82 \\
\hline $\mathrm{LP} \mathrm{Ni} \rightarrow \mathrm{N} 3=\mathrm{C} 10($ oxime$)$ & 2.49 \\
\hline $\mathrm{LP} \mathrm{Ni} \rightarrow \mathrm{N} 2-\mathrm{O} 1$ (oxime) & 1.91 \\
\hline $\mathrm{LP} \mathrm{Ni} \rightarrow \mathrm{N} 3-\mathrm{O} 2$ (oxime) & 1.18 \\
\hline
\end{tabular}

\section{CONCLUSIONS}

The geometry optimization of 1-(2,6-Dimethylphenylamino)propone-1,2-dione dioxime ligand and its nickel (II) complex were carried out using twenty one computational methods. The calculated results were compared with the non-hydrogen bond lengths and angles measured in X-ray structures. The DFT methods generally reproduced better crystal structures of the ligand and complex than HF methods and they gave very good results especially for metal-ligand bond lengths according to HF methods. The theoretical results demonstrate that the vibrational frequency and chemical shift values calculated by DFT methods are in good concordant with the experimental data. The electronic properties of the ligand and its complex were researched by using the TD-DFT method. The calculated data disclose that the electronic transitions are mainly assigned to $\pi \rightarrow \pi^{*}$ for the ligand and MLCT and LLCT for its complex. The natural charges on ligand and its nickel (II) complex were derived from natural bond orbital (NBO) analysis. The general view of the natural charges attribute to a large amount of charge donation from ligands to $\mathrm{Ni}$, when compared $\mathrm{Ni} \rightarrow$ ligands back donation.

\section{REFERENCES}

[1] Chakravorty A. Structural chemistry of transition metal complexes of oximes. Coord Chem Rev 1974; 13: 1-46.

[2] Deveci P, Taner B, Kılıc Z, Solak, AO, Arslan U, Özcan E. Synthesis, electrochemical and structural characterization of novel azacrown ether containing macrocyclic redox-active vic-dioxime ligand and its mononuclear transition metal complexes: Application of DEPT, HSQC, HMBC-NMR and cyclic voltammetry. Polyhedron 2011; 30: 1726-1731.

[3] Moon S, Case DA. A comparison of quantum chemical models for calculating NMR shielding parameters in peptides: Mixed basis set and ONIOM methods combined with a complete basis set extrapolation. J Comput Chem 2006; 27(7): 825-836.

[4] Brandenburg JG, Maas T, Grimmea S. Benchmarking DFT and semiempirical methods on structures and lattice energies for ten ice polymorphs. J Chem Phys 2015; 142: 124104-1-124104-11.

[5] Matczak P. Assessment of various density functionals for intermolecular $\mathrm{N} \rightarrow \mathrm{Sn}$ interactions: The test case of poly(trimethyltin cyanide). Comput Theor Chem 2015; 1051: 110-122.

[6] Li L, Zhang S, Zhang JSH, He X. Assessing the performance of popular QM methods for calculation of conformational energies of trialanine. Chem Phys Lett 2016; 652:136-141.

[7] Antonov L, Kurteva V. Tautomerism in 1-phenylazo-4-naphthols: Experimental results vs quantumchemical predictions. Dyes Pigm 2011; 92: 714-723. 
[8] Pisani C. Local techniques for the ab initio quantum-mechanical description of the chemical properties of crystalline materials. J Mol Struct 2003; 621: 141-147.

[9] Kaya Y, Icsel C, Yilmaz VT, Buyukgungor O. A palladium(II) complex containing both carbonyl and imine oxime ligands: Crystal structure, experimental and theoretical UV-vis, IR and NMR studies. Spectrochim Acta Part A 2013; 108: 133-140.

[10] Zülfikaroğlu A, Taş M, Batı H, Batı B. The synthesis and characterization of substituted aminomethylglyoximes and amino phenylglyoximes and their complexes with some transition metals. Synth React Inorg Met Org Chem 2003; 33(4): 625-638.

[11] Hökelek T, Zülfikaroğlu A, Batı H. 1-(2,6-Dimethylphenylamino)propane-1,2-dione dioxime. Acta Cryst 2001; E57: o1247-o1249.

[12] Batı H, Zülfikaroğlu A, Taş M, Andaç Ö, Harrison WTA. Bis[1-(2,6-dimethylanilino)propane-1,2dione dioximato]nickel(II). Acta Cryst 2005; E61: m2033-m2035.

[13] Sakıyama H, Oshima M, Suzuki S, Nishida Y. Several Molecular Orbital Computations for a Dinuclear Nickel(II) Complex. Compt Chem Jpn 2009; 8(2): 87-92.

[14] Reed AE, Curtiss LA, Weinhold F. Intermolecular interactions from a natural bond orbital, donoracceptor viewpoint. Chem Rev 1988; 88(6): 899-926.

[15] Frisch MJ, Trucks GW, Schlegel HB, Scuseria G.E, Robb MA, Mennucci B, Petersson GA, Nakatsuji H, Caricato M, Li X, et al. Gaussian 09, Revision C.01; Gaussian, Inc.: Wallingford, CT, 2009.

[16] Dennington, R.; Keith, T.; Millam, J. GaussView, Version 5; Semichem Inc.: Shawnee Mission, KS, 2009.

[17] Kohn W, Becke AD, Parr RG. Density Functional Theory of Electronic Structure. J. Phys. Chem 1996; 100: 12974-12980.

[18] Becke AD. Density-functional thermochemistry. III. The role of exact Exchange. J Chem Phys 1993; 98(7): 5648-5652.

[19] Becke AD. Density-functional exchange-energy approximation with correct asymptotic behavior. Phys Rev A 1988; 38: 3098-3010.

[20] Peng C, Ayala PY, Schlegel HB, Frisch MJ. Using Redundant Internal Coordinates to Optimize Equilibrium Geometries and Transition States. J Comput Chem 1996, 17(1): 49-56.

[21] Dewar MJS, Zoebisch EG, Healy EF, Stewart JJP. AM1: A New General Purpose Quantum Mechanical Molecular Model. J Amer Chem Soc 1985; 107: 3902-3909.

[22] Stewart JJP. Optimizationof parameters of semiempirical methods I. Method. J Comput Chem 1989; 10(2): 209-220.

[23] Stewart JJP. Optimization of parameters for semiempirical methods V: Modification of NDDO approximations and application. J Mol Model 2007; 13: 1173-1213. 
[24] Wolinski K, Hinton J, Pulay P. Efficient implementation of the gaugeindependent atomic orbital method for NMR chemical shift calculations. J Amer Chem Soc 1990; 112: 8251-8260.

[25] Runge E, Gross EKU. Density-Functional Theory for Time-Dependent Systems. Phys Rev Lett 1984; 52: 997-1000.

[26] Bauernschmitt R, Ahlrichs R. Treatment of electronic excitations within the adiabatic approximation of time dependent density functional theory. Chem Phys Letter 1996; 256: 454-464.

[27] Glendening ED, Reed AE, Carpenter JE, Weinhold F. NBO Version 3.1, TCI, University of Wisconsin, Madison, 1998.

[28] Gül A, Bekaroğlu Ö. Syntheses of N,N'-bis(4'-benzo[15-crown-5]- diamino-glyoxime and its complexes with copper(II), nickel(II), cobalt( III)-palladium(II), platinum(II) and uranyl(VI). J Chem Soc Dalton Trans 1983; 2537-2541.

[29] Sevindir HC, Ersöz M, Mirzaoğlu R. The synthesis of three unsymetrical vic-dioximes and their complexes with some transition metals. Synth. React. Inorg. Met.-Org. Chem 1994; 24(3): 419-426.

[30] Deveci MA, İrez G, Mercimek B, Bedük AD, Sarıkavaklı N. The synthesis and Ni(II), Co(II) and $\mathrm{Cu}$ (II) complexes of three new unsymmetrical vic-dioxime. Synth React Inorg Met.-Org Chem 1995; 25(10): 1699-1706.

[31] Kowalczyk I, Bartoszak-Adamska E, Jaskolski M, Dega-Szafran Z, Szafran M. Structure of 1H-2oxo-2,3-dihydroimidazo[1,2-a]pyridinium perchlorate studied by X-ray diffraction, DFT calculations and by FTIR and NMR spectroscopy 2010. Journal of Molecular Structure, 976(2010), 119-128.

[32] Gorelsky SI. SWizard Program Revision 4.5, University of Ottawa, Ottawa, 2010.

[33] Kaya Y, Icsel C, Yilmaz VT, Buyukgungor O. Palladium(II) and platinum(II) complexes of a new imineoxime ligand: Structural, spectroscopic and DFT/time dependent (TD) DFT studies. J.Org. Met. Chem 2014; 752: 83-90.

[34] Kaya Y, Yilmaz VT, Taner A, Buyukgungor O. Experimental and theoretical DFT studies of structure, spectroscopic and fluorescence properties of a new imine oxime derivative. J Mol Struct 2012; 1024: 65-72. 